\title{
Evaluation of Results of Operative Treatment of Types A Supracondylar Femoral Fractures by Dynamic Condylar Screw (DCS)
}

\author{
Maajid Shabeer Peerzada ${ }^{1}$, Nayyarandildar Malik ${ }^{2}$, Qazi Manaan Masood ${ }^{3}$ \\ ${ }^{1}$ Post Graduate Scholar Department of Orthopaedics GMC Srinagar J \& K \\ ${ }^{2}$ Post Graduate Scholar Department of Anaesthesia SKIMS Srinagar J \& K. \\ ${ }^{3}$ Post Graduate Scholar Department of Orthopaedics GMC Srinagar J \& K
}

\begin{abstract}
Supracondylar fractures of the femur although uncommon, are very challenging injuries to treat. Supracondylar femur fractures are complexinjuries, difficult to manage and associated with potential complications ${ }^{(I)}$ 'Treatment of these fractures have been a controversial subject over the past two decades. There has been a changing philosophy towards surgical treatment of supracondylar fractures of femur ${ }^{2,3,4,5,6}$ Material and methods: This was a hospital based prospective study conducted on 60 patients of fresh supracondylar femoral fractures admitted in Bone and joint Hospital Barzulla from January 2012 to January 2015.These patients were followed up for 1 year and parameters like union, range of motion and time for healing were recorded Schatzker ${ }^{5}$ and Lambert criteria were used to grade the results. Results: The age of the patients ranged from 18-72 years. There were 36 males and 24 females .Road traffic accident was the most common mode of trauma, followed by fall from height. All fractures were of AO type A. Results were excellent to good in $80 \%$ patients, fair in $17 \%$ and poor in $3 \%$ patients.
\end{abstract}

Keywords: Dynamic condylar screw, supracondylar femur, fracture, osteosynthesis.

\section{Introduction}

Supracondylar fractures of the femur although uncommon, are very challenging injuries to treat.Supracondylar femur fractures are complexinjuries, difficult to manage and associated with potential complications ${ }^{(1)}$.These fractures occur in two different age groups - due to different types of injuries. In young patients these fractures occur due to high velocity injury e.g. Road traffic accidents, fire arm injuries and sport's injuries. While in elderly patients usually low velocity injury like fall during walking, results in supracondylar fractures of the femur. Treatment of these fractures has been a controversial subject over the past two decades. There has been a changing philosophy towards surgical treatment of supracondylar fractures of femur ${ }^{2,3,4,5,6}$

Distal femoral fractures aremore likely in patients who have osteoporosis and in patients who have had prior artificial knee replacement surgery ${ }^{(7)}$. Successful treatment of intraarticular fractures especially in weight bearing joint requires restoration andmaintenance of the congruity of the two articular surfaces ${ }^{(8)}$ Involvement of the articular surface demands acongruent anatomic reduction to prevent or minimize posttraumatic arthritis and provide bone stock for later knee replacement or fusion ${ }^{9,10 .}$

Although managed conservatively in the initial era but with improvement in the available implants and surgical techniques, operative treatment is now ${ }^{11}$ considered as a standard treatment option .Internal fixation allows early ambulation and range ${ }^{12}$ of motion which avoids knee stiffness. There are number of options available for fixation of these ${ }^{13}$ fractures, including distal femur locking plate ,dynamic condylar screw (DCS) and retrograde ${ }^{14}$ intramedullary supracondylar nail .

\section{Material and Methods}

This was a hospital based prospective study conducted on 60 patients of fresh supracondylar femoral fractures admitted in Bone and joint Hospital Barzulla from January 2012 to January 2015.Patients were initially resuscitated in emergency ward following ATLS protocol .Primary treatment was given in the form of splintage,antiseptic dressing, antibiotics, analgesics, anti-inflammatorydrugs and intravenous fluids. Routine investigationswere doneand initial radiographs taken in antero-posterior and lateralviews. Fractures were classified according to AOclassification.Of 30 patients 30 were $\mathrm{A} 1 ; 24$ were $\mathrm{A} 2$ and 6 were $\mathrm{A} 3$ type.

\section{Inclusion Criteria}

1) AO type "A" supracondylar fracture.

2) Both sexes

3) Age 18 years and above.

Exclusion Criteria:

1) Lower diaphyseal fractures of femur.

2) Pathological fractures.

3) AO type "B" and "C" fractures

4) Active infections any where in the body.

5) Medically unfit patients.

After taking a proper history and meticulous physical examination the patients were prepared for the surgery. Templating on the antero-posterior and lateral views were done before the operation as pre-op preparations. The patients were operated under spinalanesthesia. Under all aseptic precautions, under tourniquet control in spine position with a pillow under knee via standard lateral approach skin incision was made and vastuslateralis was elevated from lateral inter-muscular septum.As per standard methodDynamic condylar screw plate system was fixed. 


\section{International Journal of Science and Research (IJSR) \\ ISSN (Online): 2319-7064 \\ Index Copernicus Value (2013): 6.14 | Impact Factor (2014): 5.611}

Minimum four $4.5 \mathrm{~mm}$ cortical screws engaging 8 cortices were put in proximal fragment while two $6.5 \mathrm{~mm}$ cancellous screws were put in distal fragment in addition to condylar screw. In comminuted fractures the , area of comminution was exposed with care without much soft tissue dissection so that the fragments will maintain soft tissue attachment and biology will be maintained without going for anatomical reduction of fragments.Intravenous antibiotics were given for 5 days followed byoral antibiotics and analgesia.Patients were allowed only toe touch weight bearing for first six weeks. Partial weight bearing was started after reviewing xray at six weeks. Full weight bearing was allowed at three months.

Roentgenographic union was considered satisfactory when plain $\mathrm{x}$ rays showed bone trabeculae or cortical bone crossing the fracture site.Patients were reviewed at 2 weekly intervaks for first 6 weeks and thereafter every six weeks up six months and then every three months interval up to one year. Final assessment of all the patients was done at one year. ${ }^{5}$ Schatzker and Lambert Criteria were used to grade the results.

\section{Results}

There were 36 males (60\%) and 24females (40\%) with a male to female ratio of $3: 2$. The age range was from 18 years to 72 years with mean age of 42 years. 42 patients $(70 \%)$ were aged $25-50$ years, $20 \%$ were below 25 years and $10 \%$ above 50 years. $38(63.33 \%)$ patients had fractures on right side and 22(36.66\%) patients on left side. Average stay in hospital was 18.8 days, most patients quickly regained mobility after surgery. All patients achieved full extension.

Table 1: Range of Movements

\begin{tabular}{|c|c|c|c|}
\hline S.NO & Flexion & No of patients & Percentage \\
\hline 1 & More Than 1200 & 30 & $50 \%$ \\
\hline 2 & Between $90-1200$ & 20 & $33.5 \%$ \\
\hline 3 & Less than 900 & 10 & $16.5 \%$ \\
\hline
\end{tabular}

Table 2: Time for Radiological Union.

\begin{tabular}{|c|c|c|}
\hline Time of union & No of patients & Percentage \\
\hline $0-8$ weeks & 16 & $26.5 \%$ \\
\hline 8-16 weeks & 42 & $70 \%$ \\
\hline More than 16 weeks & 2 & $3.5 \%$ \\
\hline
\end{tabular}

Table 3: Grading of the results using. ${ }^{5}$ Schatzker and Lambert Criteria

\begin{tabular}{|c|c|c|}
\hline Result at 1 year & No of patients & Percentage \\
\hline Excellent & 36 & $60 \%$ \\
\hline Good & 12 & $20 \%$ \\
\hline Fair & 10 & $17 \%$ \\
\hline Poor & 2 & $3 \%$ \\
\hline
\end{tabular}

\section{Complications}

2 case had superficial infection which was treated with dressings and antibiotics No case had deep infection. 6 patients $(10 \%)$ had knee pain of moderate nature which responded well to oral analgesics. The cause of pain was degenerative osteoarthritis, due to old age. Ten patients $(16 \%)$ were using walking stick as per instructions for osteoarthritis.

\section{Discussion}

Supracondylar fractures of the femur are often difficult to treat and these remain difficult surgical challenge even for the experienced surgeons because these require careful management to obtain good cosmetic and functional results.

The DCS is an effective method of treating supra condylar fracture of the femur with a wide range of advantages. However, extensive soft tissue dissection can lead to infection and frequent need for bone grafting. Indirect reduction and bridge plating with DCS can produce favorable results in ${ }^{15}$ complex distal femur fracture.

In our study males dominated and were mostly in the age group (30-50 years) which is the productive and involved in outdoor activities and hence resulting in trauma.In Muslim countries the male to female ration is high as compared to western studies because of less active participation of females in outdoor activities in those societies ${ }^{16,17}$.

In our study Road traffic accident was the most common mode of trauma accounting for $66 \%$ of cases which is comparable to KM Marya ${ }^{18}$ andAustralian study ${ }^{19}$ reporting RTA as the most common mode of trauma in $92 \%$ and $82 \%$ respectively.

In our study $80 \%$ of the patients had excellent to good results which are comparable to Christodoulou et al ${ }^{17}$ reporting excellent results in $51 \%$, good in $30 \%$, fair in $4 \%$, poor in $8 \%$ in total of 37 patients.

Average time for union in present study was 15 weeks. Christodoulou et al $^{17}$ reported time for union to be 20 weeks while a study at Addenbrook's ${ }^{20}$ hospital, Cambridge reported it to be 11.3 weeks. This vast difference in time taken for union in difference studies was due to differences in postoperative mobilizations protocols and criteria for union so cannot be compared to present series. Range of motion of knee achieved at final follow-up was comparable to international studies ${ }^{2,3} .3 .5 \%$ had superficial infection. The reported rate is zero to eight percent in other studies which is comparable $\mathrm{e}^{17,20}$.

\section{Conclusion}

From our study it is concluded that DCS is an acceptable and effective means of treating distal femoral fractures.However care is to be taken to preserve soft tissueenvelop in order to achieve acceptable outcome .Younger age group (age <50yrs) had betterfunctional outcome. 


\section{International Journal of Science and Research (IJSR) \\ ISSN (Online): 2319-7064}

Index Copernicus Value (2013): 6.14 | Impact Factor (2014): 5.611

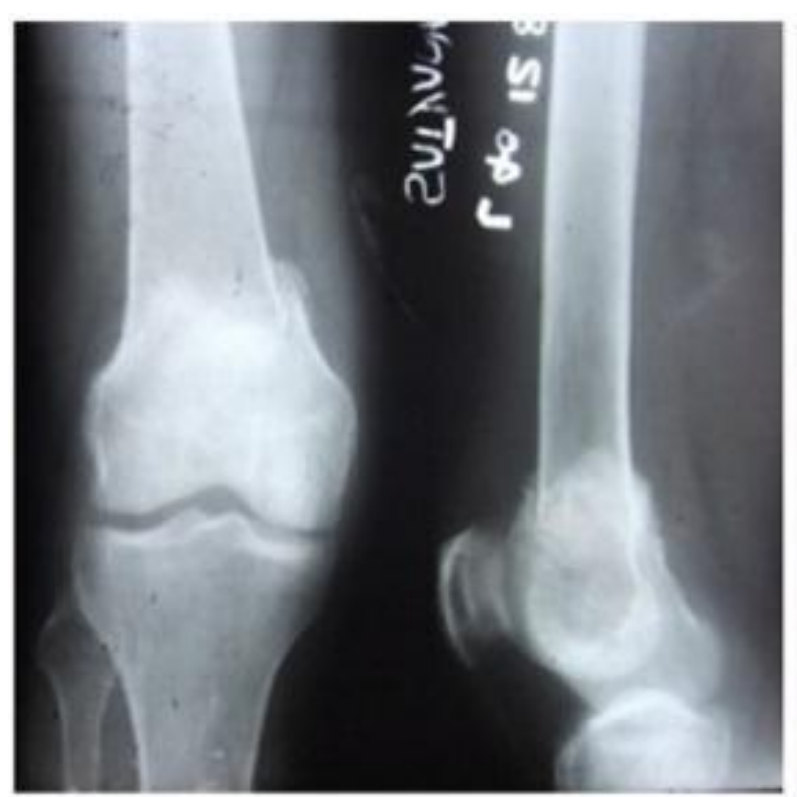

\section{References}

[1] Dar GN, Tak SR, Kangoo KA, Halwai MA. Bridge plate osteosynthesis using dynamic condylar screw (DCS) or retrograde intramedullary supracondylar nail (RIMSN) in the treatment of distal femoral fractures: comparison of two methods in a prospective randomized study. UlusTravmaAcilCerrahiDerg. 2009 Mar;15(2):148-53

[2] Giles JB., DeleeJC.,Heekman JD. Supracondylar intercondylar fractures of the femur - treated with a supracondylar plate and lag - screw. JBJS, 1982, 64 A, 868.

[3] Healy WI., Brooker AF. Distal femur fractures: comparison of open and closed methods of treatment. ClinOrthop. 1983, 174, 166.

[4] Mise BD., BncholRW., Grogan DP. Surgical treatment of displaced, comminuted fractures of the distal end of the femur.JBJS. 1082, 64- A, 871.

[5] Schatzker J., Lambort DC. Supracondylar fractures of the femur. ClinOrthop. 1997, 138,77.

[6] Zickle RE., FiettiVG.,Lawsing TF. A new intramedullary device for the distal third of the femur.ClinOrthop. 1997, 125.

[7] Brett D, Crist MD, Gregory J, Della Rocca, Yvnne M. treatment of acute distal femur Fractures. Orthopedics 2008; 31: 681.

[8] Healy WL and Brooker AF Jr: Distal femoral fractures: comparison of open and closed methods of treatment. ClinOrthop 1983; 174:166-72.

[9] Olerud S. Operative treatment of supracondylar-inter condylar fractures of the femur: technique and results in fifteen cases. J Bone Joint Surg 1972; 54:1015-32.

[10] Schatzker J, Lambert DC. Supracondylar fractures of the femur. ClinOrthop 1979; 138:77-83.

[11] Nasr AM, Mcleod I, Sabboubeh A, Maffulli N. Conservative or surgical management of distalfemoral fractures. A retrospective study with a minimum five year followup. ActaOrthop Belg. 2000;66:477-83.

[12]Zlowodzki M,Bhandari M, Marek DJ, Cole PA, Kregor PJ.Operative treatment of acute distalfemur fractures: systematic review of 2 comparative studies and 45 case

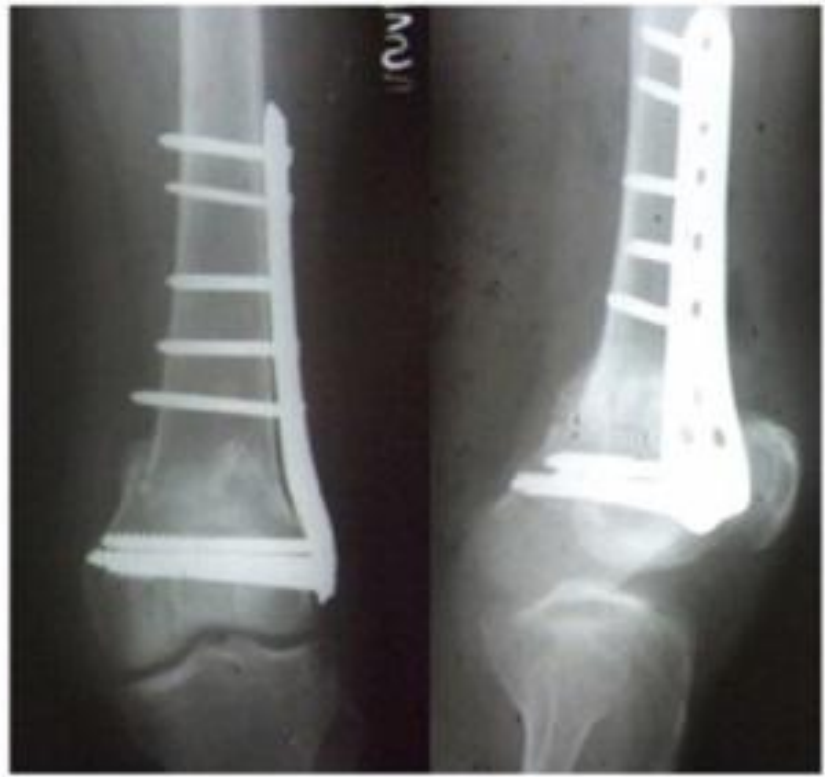

series (1989 to 2005).J Orthop Trauma. 2006 May;20(5):366-71.

[13] Ricci WM, Streubel PN, Morshed S, Collinge CA, Nork SE, Gardner MJ. Risk factors for failure oflocked plate fixation of distal femur fractures: an analysis of 335 cases. J Orthop Trauma. 2014 Feb;28(2):83-9.

[14] Heiney JP, Barnett MD, Vrabec GA, Schoenfeld AJ, Baji A, Njus GO. Distal femoral fixation: abiomechanical comparison of trigen retrograde intramedullary (i.m.) nail, dynamic condylar screw (DCS), and locking compression plate (LCP) condylar plate. J Trauma. 2009Feb;66(2):443-9.

[15] Canale ST, Beaty JH, Whittle AP. Fractures of Lower Extremity. Campbell's operative Orthopaedics.Philadelphia: Mosby Elsevier; 2008.p.3170-3.

[16]ftikar Ali, Shahabuddin: Surgical outcome of supracondylar and intercondylar fractures femur in adults treated with dynamic condylar screw. JPMI2011 vol 2 no 1:49-55

[17] Christodoulou A. etal,Supracondylar fractures treated in elderly patients treated with dynamic condylar screw and retrograde intramedullary nail: a comparative study of the two methods.ArchOrthopTraumaSurg 2005;125:73-9

[18] MaryaKM.Critical evaluation of management of fractures of shaft femur by Brooker - Willis nails. J Bone Joint Surg Am 2003;85:2093-96

[19] Majkowski RS, Baker As. Interlocking nails for femoral fractures an initial experienceInjury 1991;22:93-96

[20] Schwring DJ, etal.Fractures of the distal femur treated with the AO dynamic condylar screw. J Bone Joint Surg Br 1992;74:122-5

\section{Volume 4 Issue 12, December 2015}

